\section{Verifiable CPD}

This issue sees the launch of the new $B D J$ verifiable CPD initiative. This initiative is being operated in partnership with Eastman Continuing Professional Development, and provides UK dentists with the opportunity to satisfy 48 hours of their verifiable CPD requirements per year. This is well in excess of the minimum requirements, but we hope that dentists will use this initiative sensibly by selecting topics where they have identified a learning need rather than simply making up the hours by choosing topics at random.

This is not the first CPD initiative that the $B D J$ has introduced. From July to December 1999 the $B D J$ linked with Primary Dental Care, the journal of the Faculty of General Dental Practioners, to jointly publish questions based on CAL distance learning programmes produced by The Department of Health. Two subjects were selected, endodontics and cross infection control. Despite the fact that CPD was in its early stages and not compulsory we received a very good response from the profession and the format seemed to be popular with those who participated.

In 2001 the $B D J$ worked with another partner, Redbus CPD, to launch an internet-based programme based on a $B D J$ seminar on implants. The seminar was filmed on video and then prepared (by Redbus) for dentists to purchase as part of their CPD requirements via the internet. This was an exciting project but the number of dentists who were prepared to obtain CPD by attending a seminar via the internet instead of physically attending was disappointing, despite the obvious advantage of having the material to watch whenever you wanted (and as many times as you wanted). I have no doubt this method of learning will increase as people become more used to broadband internet connections and video-streaming to obtain films for television, but it is early days yet. I also suspect that dentists, being in a fairly solitary professional environment most of their working day, prefer the inconvenience and additional cost of attending courses because of the opportunity to mix socially with their colleagues.
This time the $B D J$ has adopted a more traditional approach to CPD, and one adopted by several other dental journals. We are simply asking people to complete a short multiple-choice questionnaire based around two of the articles in each issue and send them to the Eastman for marking. The answers to the questions will be published a month later in the $B D J$, so people can check their accuracy for themselves. People submitting their answers to the website www.bdjeastmancpd.com will receive the answers immediately rather than having to wait a month to see the answers in the $B D J$.

Certificates will be issued by the Eastman at the completion of the year. They will be sent by post annually to those without an e-mail reply and can be downloaded by those with an e-mail address. The Eastman can also take feedback via the internet, but not by post. The concept has obviously been designed for verifiable CPD for UK dentists, but because the site is internet based it can also be used by dentists outside the UK for their own educational interest.

The template for this CPD model came from the Journal of the American Dental Association (JADA). I have quite unashamedly copied their CPD template, having seen its success when I visited the American Dental Association last summer. Its simplicity appealed to me, and the link with a dental institution seemed so obvious that I found it difficult to believe we had not thought of it ourselves (but so many really good ideas are like that). I was delighted when the Eastman agreed to help us develop the concept and provide the clinical expertise, the administration and the operation of marking the submissions.

Participation in the programme will be free of charge to BDA members and will cost non-members a nominal $£ 10$ administration charge. All the details can be found on the CPD pages inside this issue, and we look forward to seeing this programme develop in the years ahead.

Mike Grace, Editor m.grace@bda-dentistry.org.uk doi:10.1038/sj.bdj.4810302 